The most important work to be done on the present cruise is to mark whales off the north-west coast of Australia in the southern winter (July and August). First, however, the ship will make a preliminary survey of the Benguela Current off the coast of SouthWest Africa, which is a region of interest because cold water from the ocean depths wells up like a spring to the surface. The William Scoresby formerly surveyed a similar region off the west coast of South America, where the deep water brings certain nutrient salts to the surface, and causes a rich development of the marine fauna and flora.

She will call at Cape Town, East London and Mauritius, and during the voyage will undertake various oceanographical work both in shallow water, and where the bottom slopes down to oceanic depths. Little is known of the water masses and currents of the central Indian Ocean, and during the passage from Mauritius to Fremantle it is expected that valuable observations can be made. If time permits, some trawling may be carried out in Australian waters, and then about two months will be spent off the north-west of Australia. Before the War the William Scoresby marked some thousands of whales in the Antarctic, but this was done in the summer months; it is now necessary to mark them in the winter when they migrate towards the equator. At this time of year an important species, the humpback whale, is known to congregate near the northwest Australian coast.

\section{AGAR FROM BRITISH SEAWEEDS}

A

WELL-ILLUSTRATED account has been 1 published* of the manifold investigations which led to the exploitation of the available supplies of the British seaweeds Gigartina stellata Batt. and Chondrus crispus (L.) Stackh. as a source of agar. The book is of value in many different directions. Quite apart from the economic importance of the achievement, these researches afford much information on the growth and seasonal development of these seaweeds, and especially of Gigartina. They thus provide one of the most important contributions to the autecology of a red seaweed that has so far been published. Moreover, the very extensive explorations which were necessary and which are a testimony to the immensity of the effort involved have afforded much inform. ation of general ecological interest with reference to the marine flora, particularly that inhabiting the shores of the Scottish Isles. The various botanists who co-operated in these researches, and particularly Prof. L. Newton, who played an important part, are heartily to be congratulated on the result. It is to be regretted that work of such marked scientific importance can only be achieved when war-time exigencies demand it.

Up to 1939 most of the agar used in Great Britain and other countries was imported from Japan. Even before the Japanese became belligerents, the need to find substitutes became urgent, so that the compre. hensive investigations described in this memoir were initiated already early in the War. Of the various red seaweeds that seemed likely to provide a suitable

* A Study of certain British Seaweeds and their Utilization in the Preparation of Agar. By S. M. Marshall, L. Newton and A. P. Orr ; with the collaboration of P. W. Carter, E. Conway, K. M. Drew, E. A. Lewis, J. Macnaughtan, $H$. T. Powell and others. Edited by Office, 1949.) 278. 6d. net. agar, only the two already mentioned can be gathered in sufficiently large quantities, and Gigartina is far more abundant than the almost equally suitable and better-known Chondrus. It is therefore not surprising that the greater part of the memoir concerns itself with the former. Except for parts of Northumberland, extensive growths of Gigartina stellata are met with only on the west coast, the richest localities being those of the Clyde sea-area, where yields of 8-30 lb. per yard of coast were obtained. This seaweed favours rather gently sloping rock surfaces on exposed or semi-exposed coasts and occurs usually at the base of the Fucus serratus zone, either as separate tufts or as an almost continuous belt, sometimes as much as twenty yards wide; it is frequently associated with Himanthalia lorea.

Little new information on the life-cycle of Gigartina stellata is provided. The occurrence of fertilization remains as doubtful as ever, and even these intensive investigations have not brought to light any tetrasporangiate plants. On the other hand, the detailed studies of seasonal development, that had to be undertaken to determine the best methods of harvesting, have added considerably to our knowledge of Gigartina. Although in some districts it behaves as an annual, the plants commonly last for three or four years, the new growth in spring arising either from persisting parts of old erect fronds or often in large part from the conspicuous attaching disk. This increases in thickness with the years and exhibits a number of layers, one probably corresponding to each year of growth. Much the same is true of Chondrus, where, however, the holdfast is less firmly attached. The growth of the erect fronds terminates between July and September, and soon after this the gelstrength is at a maximum, while the period of maximum carpospore-discharge lasts from September until December.

These observations indicated that, during harvesting, care must be taken not to destroy or remove the holdfast, so that hand-picking rather than shearing was recommended. Furthermore, it was concluded that a single yearly harvest between July and September would be most appropriate, when a maximum yield would be obtained and there would be no interference with the discharge of spores from remaining plants. It is of interest that these conclusions can be correlated with the past experience of some of the crofters on the Scottish Isles who "are aware that the maximum growth has developed by August and September, that the extract is at its best, that the dried weed keeps better and that it is most easily torn from the holdfast at that time".

The extraction was carried out by boiling in lime water and removing the residue. The cooled extract sets to a weak gel. Various methods of hardening the latter were tested, but the one finally adopted was to heat the extract with potassium hydroxide and neutralize with hydrochloric acid; the amount of the former should not exceed 15 per cent of the dry weight of the extract. Best results were obtained by carrying out the potassium hydroxide treatment in an autoclave for eight hours at $20 \mathrm{lb}$. per sq. in. or for two hours at $40 \mathrm{lb}$. per sq. in. The resulting agar has a deep yellow colour which can be removed by treatment with activated charcoal. It has a lower melting point, dissolves much more readily and is denser when set than the Japanese product. It contains a much greater percentage of inorganic material ; however, this is not an impurity but forms part of the gel complex.
F. E. Fritsch 